\title{
Design a Wireless Automated Solar Powered Irrigation Control System for Smart Universities Green Areas Water Management
}

\author{
Yasser M. Alharbi ${ }^{1 *}$, Mohamed S. Soliman ${ }^{1,2}$, Farhan A. Salem ${ }^{3}$, Ahmad A. Alahmadi ${ }^{1}$, \\ H. Abeida ${ }^{1}$ and Yahya S. H. Khraisat ${ }^{1,4}$ \\ ${ }^{I}$ Department of Electrical Engineering, Faculty of Engineering, Taif University, Taif, Kingdom of Saudi Arabia. \\ ${ }^{2}$ Department of Electrical Engineering, Faculty of Energy Engineering, Aswan University, Aswan, Egypt. \\ ${ }^{3}$ Department of Industrial Engineering, Faculty of Engineering, Taif University, Taif, Kingdom of Saudi Arabia.
}

${ }^{4}$ Department of Electrical and Electronics Engineering, Al-Balqa' Applied University/Al-huson University College, Irbid, Jordan.

\begin{abstract}
As a contribution in developing smart universities and achieving economy and comfort in terms of water-labor-saving as well as, improved water-energy efficiency, the present work provides both a conceptual design and a blueprint for practical implementation of wireless standalone solar powered smart irrigation control systems for managing water using in green areas of smart universities. The proposed system design consists of five sub-modules, each of which is planned to be standalone solar powered and wireless controlled. The module consists of sensor, main control unit, actuator, local water well monitoring and managing, as well as, to supervisor's wireless module for data recording and remotely monitor the green area state, in addition, monitor the irrigation activity. Wireless communication technology is applied to transmit data between these five sub-modules. The microcontroller based main control unit module is designed and programmed with control algorithm developed to process and analyze acquired data, predict the atmosphere state and take decisions based on the day time (morning/evening) condition, available volume of water in the well and soil state (temperature and moisture). If a specific treatment is required, decision is taken by the microcontroller and proper treatment is sent wirelessly to actuator modules to implement the decision process.
\end{abstract}

Keywords: Automated irrigation system; Water saving; Wireless control; Solar power; Sensor network; Smart universities.

\section{INTRODUCTION}

Building automation also called smart building is employed in smart university design to control cost, achieve comfort, security and safety ${ }^{1-3}$. In the modern world, the prime human being occupation is in the agriculture field. Agriculture occupies around $64 \%$ of total available land and consumes around $85 \%$ of available fresh water. In addition to this, irrigation is one of the areas where power is so essential ${ }^{4}$. However, by the current irrigation systems, the management and consumption of water, energy and labour, are not efficiently employed, sometime irrigation is delayed when required or performed when it is not necessary, it may cause overwatered soil. All this result in water-energy-labor waste, as well as, low-crop yield.

The present work provides both a conceptual design and a blueprint for practical implementation, of smart wireless irrigation, standalone, and solar powered irrigation systems for managing green areas in smart universities. The design is suggested as a contribution in developing smart universities and achieving economy and comfort, in terms of water-labor-saving as well as, improved water-energy efficiency

\subsection{Literature review}

Various design solutions for smart farming and irrigation system are discussed and can be found in different research works. Some of these works are summarized next.

Employing artificial intelligence in irrigation system design can be found in ${ }^{5-7}$. In ${ }^{8}$ authors suggest a central smart irrigation system design intended to control many farms. Every farm is equipped with a computer wired to data collection module. Transmission Control Protocol/Internet Protocol (TCP/IP) over internet was used for communications between farms' and central computer. In ${ }^{9}$ a smart irrigation system is presented, the system is developed using a cloud based control system and utilizing wireless sensor networks. The acquired data by sensors about the farm and environment state are uploaded to cloud for evaluation. The cloud is remotely controlling the actuator network based on the evaluation of data acquired by sensor. Communications were done via internet. In 10 authors presented a smart irrigation system using internet of things, for application in water constrained regions, and intended to challenge power and water wastage. In the 
suggested design the environmental data were collected by sensors and sent, using internet, to the farm owner for taking decisions, to implement the decision; human labor is required. The operating cost, of the suggested design, is high, since the system involves labor and internet costs. In 11 wireless distributed sensors network, that are spread over the farm, was utilized to acquire data about the farm environment, soil and plant status including relative humidity temperature, rainfall and leaves' humidity. The collected data is sent to central control unit that programmed with control algorithm. Based on decision taken, the control unit controls the actuators like water pumps for a specific period. In ${ }^{12}$ for rice plant farms, smart irrigation system is developed utilizing wireless sensor network. The design is suggested to improve water efficiency in a country that suffers from water scarcity in summer season. Data about rice plant farms including humidity, temperature, energy, water level and light were acquired by Telosb sensor nodes. Nodes were programmed using Tinyos 2.1.2 to collect data, process, analyze and send it. Python language was used to program middleware program to upload the acquired data from the base station to the cloud server. Based on Google cloud infrastructure, a website was also implemented to display all information to the farmers in the farm.

\subsection{System methodology and working principle.}

The conceptual design and a blueprint for practical implementation, of smart, wireless, standalone, and solar powered irrigation systems for managing green areas in smart universities is to be presented. The system is developed to monitor and control the irrigation process based on ambient states and conditions on the ground, as well as, the supervisor's input. The smart farming system is developed for application around the green areas at Taif University located around the foreign languages college, but the design can be modified for any other specific green area setup. As shown in figure 1, the selected green area consists of the following green forms; $a$ ) fruitful trees (pomegranate and Raspberry) planted in two locations, the first location is planted in matrix form with four rows and 12 columns, the second location is planted with three rows and 10 columns, b) Ornamental trees and decorative bushes, $c$ ) Flowering shrubs and shrubs for making hedges, $d$ ) Green grass areas, e) $A$ water well is located at 15 meters.

The suggested system design consists of five sub-modules, each of which is designed to be standalone solar powered and wireless module. The module is; sensor, main control unit, actuator, local well monitoring and managing, as well as, to supervisor's wireless module for data recording and remotely monitor the green area state in addition, to monitor the irrigation activity. Wireless communication technology is applied to transmit data between these five sub-modules. The design is developed based on dividing all green areas at a given university into sections, each section is given an identification number, also, each section depending on the dimensions, is equipped with corresponding number of standalone, solar powered, wireless sensor and actuators modules, to acquired data and implement the taken decisions for specific section. A sensor module is specially designed and equipped with microcontroller and sensors necessary to read environmental and green section area data and state from the soil or atmosphere (climate) including soil state scanning (temperature and moisture), water levels, light intensity, humidity, temperature, wind speed rainfall and others. Each sensor module is to be placed in an identified location to cover a specific green area section and given an identification number for that location. The collected data is processed and analyzed by the control algorithm. The collected data, location identification number and decision taken are all send wirelessly to main control unit. The microcontroller based on main control unit module is designed and programmed with control algorithm, which is developed to process and analyze acquired data, predict the atmosphere state and take decisions, based on time (morning/evening), available volume of water in the well and soil state (temperature and moisture), if a specific treatment is required, and if yes, which treatment. e. g. to apply irrigation in improved water-energy efficiency manner, in green areas and allow ability to monitor and control applications of water. The taken decisions are sending wirelessly to actuator modules to implement the decision process. The main actuators in the system design include pumps (for well, surface water tank), valves, light/sound indicators and data displays. An actuators module is specially designed and equipped with microcontroller, interfaces circuits and drives (e.g. relays) necessary to activate irrigation actuators.

Another wireless module is developed to control and manage the local well and pumping water to ground storage tank and from this tank to a green area sections' actuator.

Solar photovoltaic energy is utilized as the power source for powering system modules, resulting in standalone solar powered smart system.

\section{SYSTEMS ARCHITECTURE AND HARDWARE SELECTION, DESIGN AND SYNERGISTIC INTEGRATION ISSUES}

The conceptual design and a blueprint for practical implementation, of smart irrigation is developed consisting of the following subsystems and main components; mechanical subsystem, wireless sensor modules, wireless actuator modules, control units, control algorithms, interfaces, drives and power supplies. The system design with synergistic integration of all subsystems and components is achieved by the suitable parameters selection and design, in terms of sizing, dimensions, power requirements, wiring, software integration and others. These concepts are to be applied in the next hardware selection, design and synergistic integration issues.

Among the most reliable and famous manufacturers of agricultural technology are Gill Instruments, Decagon, Apogee and Ecomatik. Hardware components can be order from any of these manufactures; also, as done in this work other reliable, cost-effective, and available at local market recourses, can be utilized. The system architecture and representation using block diagrams, including all modules, are shown in figure 2. 


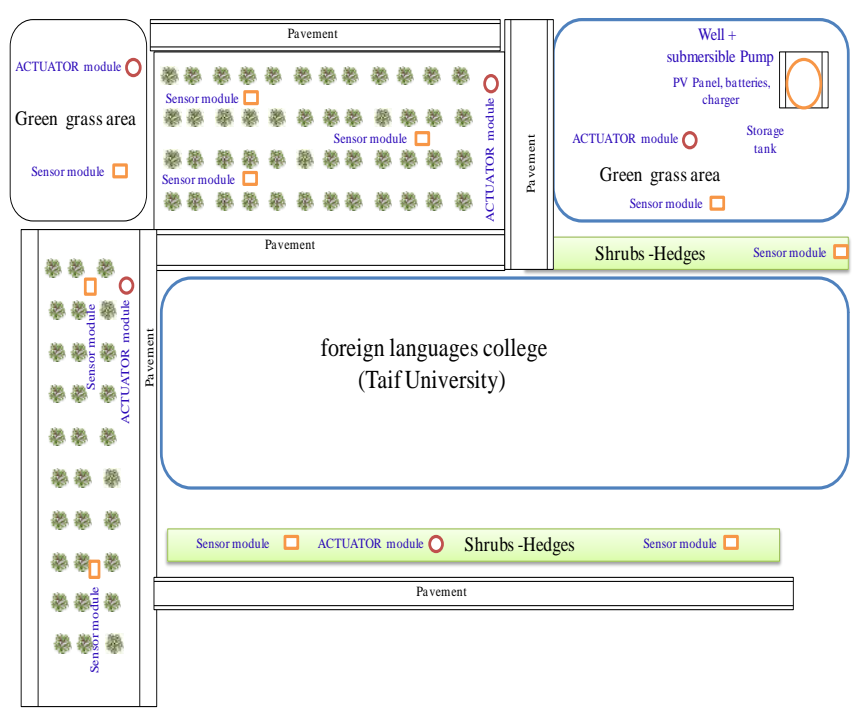

Figure 1. Pictorial diagram representing the selected green area at Taif University, green areas forms, sections and modules placement.

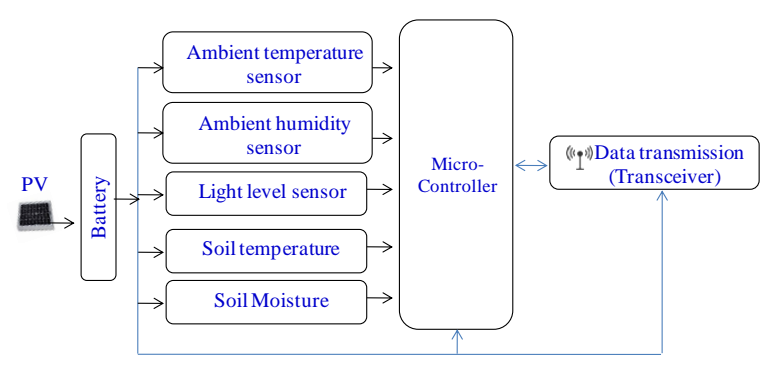

(a)

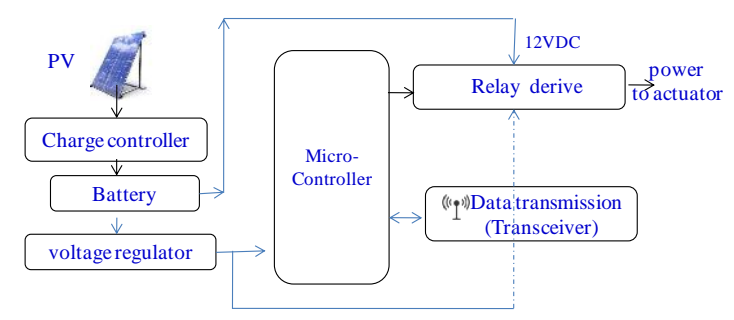

(b)

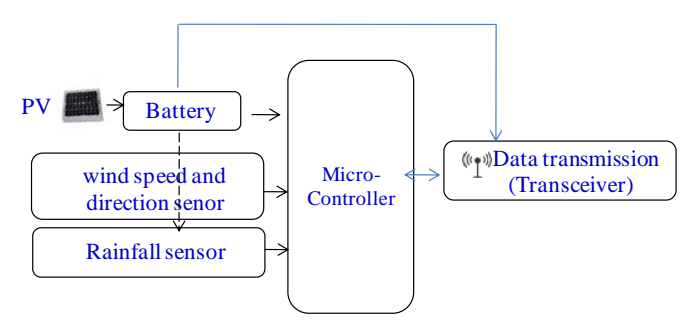

(c)

Figure 2. Block diagram representation: (a) wireless solar powered standalone sensors module design; (b) Block diagram representation of the wireless solar powered standalone actuator module design; (c) of the wireless solar powered wind speed/direction and rainfall module.

\subsection{Control unit and algorithm selection.}

Microcontroller is suitable control unit for controlling the whole smart irrigation system, as well as, controlling the operation of the modules. A good choice among microcontrollers is the ATmega 2560 based Arduino mega for controlling the system and Atmel ATmega328 based Arduino Nano for controlling the modules as shown in figure 3(a)(b).

The irrigation system is an ON-OFF system, which is switching on actuators when a condition is met, otherwise switches it off. The suitable control algorithm for such set up is the ON/OFF algorithm.

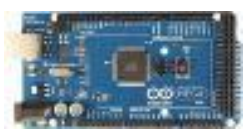

(a)

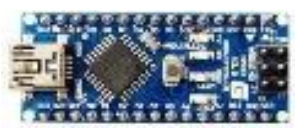

(b)
Figure 3. Microcontrollers: (a) Arduino Mega.; (b) Arduino Nano.

\subsection{The wireless Sensor module hardware selection design, and integration issues}

\subsubsection{Sensors hardware design}

The variables representing the green area's sections conditions and status, including the atmosphere (climate) and soil state, are to be acquired using a combination of the next sensors; Sensors for soil state scanning in terms of soil temperature and moisture. Sensors for reading ambient environment and atmosphere in terms of relative humidity, ambient temperature, light intensity, wind speed and rainfall possibility. Finally, Sensors to read the state of green area facilities e. g. in terms of existing water levels in the local well.

Sensors for soil state scanning; soil temperature and humidity levels can be accurately acquired using Adafruit BME280 sensor, shown in figure 4(a), it is also can be used to measure barometric pressure. Other options include Watermark § soil moisture sensor, shown in figure 4(b) and soil moisture / MULTI sensor, shown in figure 4(c). Other option can be conductivity, water content and soil temperature GS3 sensor probe (Decagon GS3), shown in figure 4(d). Hardware integration in terms of placement, soil humidity and temperature sensors are placed all times such that are covered with soil without any air gaps. Sensors for reading green area environment and atmosphere in terms of relative humidity, ambient temperature, light intensity, wind speed and rainfall possibility.

For measuring ambient temperature and humidity, different options are available, including the digital SHT3x humidity and temperature sensor, the HYT939 industrial grade humidity and temperature sensor, grove temperature and humidity sensor and finally KY-015 DHT11 sensor. All these sensors are shown in figure 5(a-d). A good option for measuring only ambient temperature is the shown in figure 5(f) waterproof DS18B20 temperature sensor. 
Predicted Rainfall possibility can be done using the Hydreon RG-11 Rain sensor, the circuit and wiring diagram is shown in figure $6(\mathrm{a}-\mathrm{b})$.

Wind speed and direction can be measured and utilizing the Davis Anemometer shown in figure 6(c). It is a device consisting of two sensors; potentiometer depending on the wind direction, changes its resistance. Meanwhile Wind speed is measured by cups that open and close a reed switch.

Light intensity is measured used LDR with circuit divider circuit, built as shown in figure 6(d). The output voltage is calculated by Eq.1

$$
V_{\text {out }}=V_{\text {in }}\left[R_{1} /\left(R_{1}+R_{L D R}\right)\right]
$$

reading the state of the water level in the existing local well can be done by Global Water WL705 Ultrasonic water level sensors in figure 6(e), another option is using submersible borehole water level sensor shown in Figure 6(f), with 5VDC operating voltage and 0/5-4.5 VDC output voltage. As an alternative, ultrasonic HC-SR04 distance sensor, shown in figure $6(\mathrm{~g})$ can be utilized to measure the water level in the well

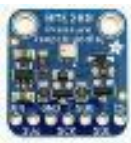

(a)

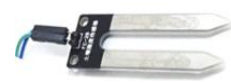

(c)

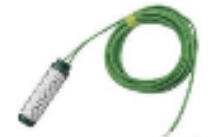

(b)

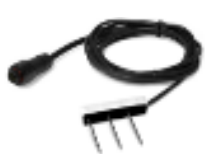

(d)
Figure 4. Sensors for soil state scanning: (a) BME280 soil temp. and hum. sensor; (b) Watermark ${ }^{\circledR}$ soil moisture sensor; (c) Soil Moisture / MULTI Sensor; (d) Decagon GS3Conductivity, and soil temperature sensor.

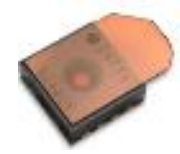

(a)

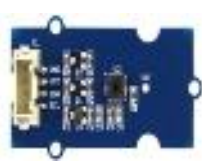

(c)

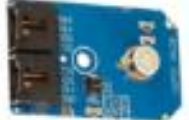

(b)

(d)

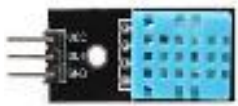

(f)

Figure 5. Sensors for reading green area environment and atmosphere: (a) humidity and temp. Digital SHT3x Sensor; (b) industrial HYT939 grade humidity and temperature sensor; (c) Grove Humidity and Temperature Sensor; (d) KY-015 DHT11 Sensor; (f) waterproof DS18B20 Temperature sensor.

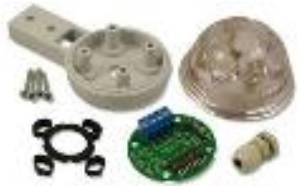

(a)

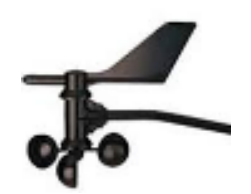

(c)

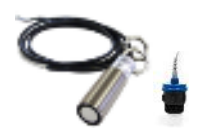

(e)

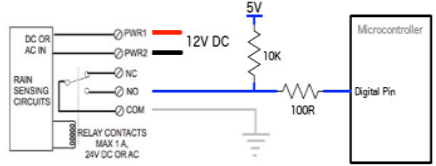

(b)

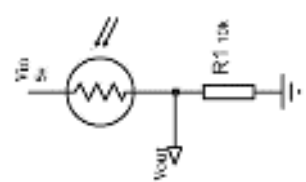

(d)

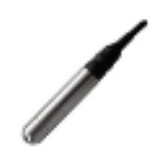

(f)

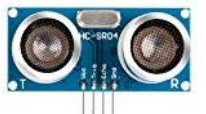

$(\mathrm{g})$

Figure 6. Sensors for reading green area environment and atmosphere: (a) Hydreon RG11 rain sensor; (b) circuit diagram Hydreon rain sensor ${ }^{13}$; (c) Davis anemometer device; (d) Light intensity based LDR sensor; (e) Global Water WL705 Ultrasonic water level sensors; (f) submersible borehole water level sensor; (g) Ultrasonic HC-SR04 Distance Sensor.

\subsubsection{Wireless sensor module design}

Wireless, standalone and solar powered sensors module encapsulating and equipped with all the selected sensors, control unit, communication module, interface circuits and power supply, are to be in this section, designed with integration, synergy and control issues. All the sensors are to be selected miniaturized, designed for the open, operating in $5 \mathrm{VDC}$ and generating output voltage up to 5VDC.

The wind speed, rainfall and water level sensors are not part of the wireless sensor module, this is because, only one of each of these sensors, is needed for the whole university's green areas, to predict rainfall, wind speed and direction. The wind speed and rainfall sensors are placed at high location; an example a pillar can be used for this purpose as shown in Figure 7 (a).

The placement and identification of sensor module: to manage and organizes irrigation process, the green area is divided into many sections with identification number. Depending on section's dimensions, a specific number of sensors modules are placed; each sensor module is used to read data variable related to local section's (green area) status, the atmosphere and soil conditions and states, process and analyze the collected data, and take decision if a specific treatment is required. Finally, all the collected data, sections' location identification number and decision(s) taken, are send wirelessly to main control unit.

Solar PV is utilized to achieve economy in terms of improved power consumption and increasing efficiency, the sensor 
module is developed to be wireless, standalone solar powered. The Mono-crystalline solar panel, shown in figure $7(\mathrm{~b})$, is selected. The dimensions of cell are $\mathrm{L}=108 \mathrm{~mm}, \mathrm{~W}=39 \mathrm{~mm}$ and Thickness $=2.5 \mathrm{~mm}$. A suitable battery choice for operating in the open farming environment with high and low temperatures and humidifies e.g. -15 to $+50^{\circ} \mathrm{C}$, are NI-MH and LI-Ion anti-high temperature batteries.

If NI-MH batteries, shown in figure 7 (c) are used then the panel is $2.5 \mathrm{~V} / 120 \mathrm{~mA}$. Meanwhile $5 \mathrm{~V} / 60 \mathrm{~mA}$ panel for lithium battery. In rainy and foggy days, solar powered sensor module, with these conditions, can operate up to three days after being full charged. The wireless communications can be implemented via Radio, Wi-Fi, or GSM Communication. The NRF24L01 transceiver module shown in figure 7(d) is good choice for radio communication, meanwhile, the ESP8266 Wi-Fi module, shown in figure 7 (e), is a good selection for transmission via internet. Finally, for GSM based communication, the GSM Module SIM900 shown in figure 7 (f) can be used.

The control unit for this design is shown in figure 3 (b) microcontroller-based Arduino Nano board. To step up voltage to constant 5VDC, a good choice is the voltage regulator circuit DC boost step up converter module to $5 \mathrm{~V}$ shown in figure $7(\mathrm{~g})$.

In figure $7(\mathrm{k})$ and $7(\mathrm{l})$ are shown the pictorial diagram representing the hardware design and integration of the wireless solar powered sensor module and housing design. As shown in these two figures, hardware integration in terms of sensors placement; the wireless sensor module housing is designed such the ambient temperature, humidity sensors and the light intensity sensors are exposed to the ambient environment, while the soil temperature and moisture levels are placed all times such that and covered with soil without any air gap. The approximated height of the module above the ground level can be around $30 \mathrm{~cm}$ and more. In order to install the design deep inside the soil, a metal fixing nail (with support extension) with slots for fixing the soil state sensor, is used. The module design can be fixed to tree's trunk using a strap as shown in figure $7(\mathrm{~h})$.

\subsection{The wireless actuators module and actuators hardware selection design, and integration issues}

To implement the irrigation process in terms of taken decisions, the following actuators are required; pumps for water pumping from both the well and the surface water tank, valves, indicators (Light/sound) and data displays.

To achieve economy, reduction in power conception and utilizing solar energy, the actuators (pumps and valves) are selected low powered with operating 12 VDC voltage. A design of an actuator wireless solar power module is to be presented.

For pumping the water from the well to the surface water tank, a good selection is the $12 \mathrm{~V}$ DC submersible water pump is shown in figure 8(a) another options are the two pumps shown in figure 8(b)(c), the YM2440-30 6LPM submersible pump and VP50E 12V small solar powered submersible water pump with maximum flow of 201/min.

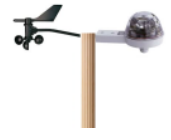

(a)

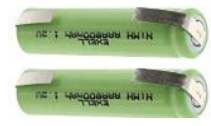

(c)

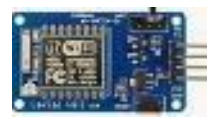

(e)

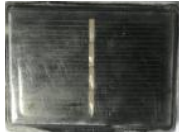

(b)

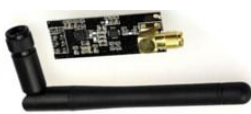

(d)

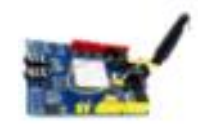

(f)

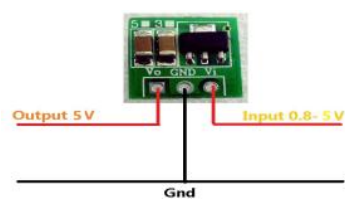

(g)

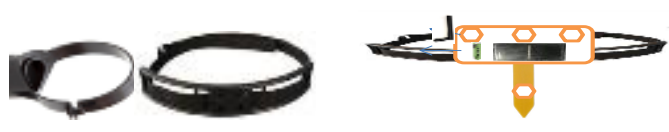

(h)

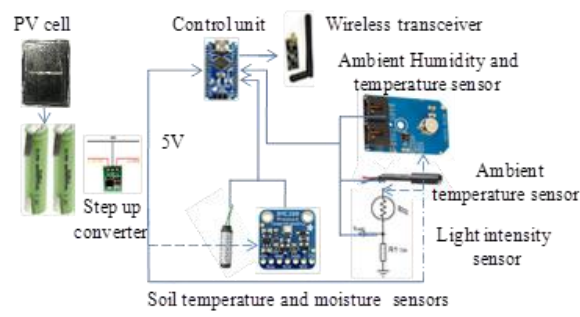

(k)

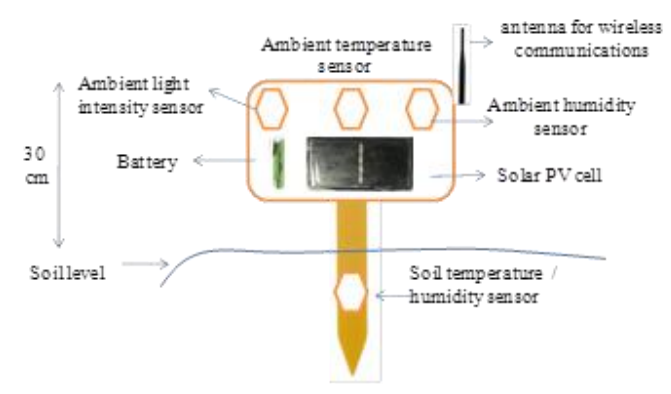

(1)

Figure 7. Proposed Sensors for green area environment and atmosphere: (a) Wind speed and rainfall sensors placement on a pillar; (b) 2.5V 120MA Mono-crystalline solar panel; (c) 1.2V/800 mAh NI-MH; (d) NRF24L01 transceiver module; (e) Global Water WL705 Ultrasonic water level sensors; (f) GSM Module SIM900; (g) Step up converter to 5 VDC module; (h) The module design to be fixed to tree's trunk using a strap; (k) The pictorial diagram representing the hardware design and integration of the wireless solar powered sensor module; (1) Wireless sensor module design; housing and hardware placements. 


\subsubsection{Wireless actuator module design}

To simplify the design installation and to achieve economy and reduction in power conception, a wireless, solar powered standalone module design for powering both the modules' components and each attached actuator (Pumps and valves) is presented in this section. The suggested module design is developed encapsulating the following component; solar system for powering and storage, control unit, drive circuits for driving the actuator and wireless communication module.

Since the actuators selected are ON/OFF type, the suitable drive interface circuit for driving, Pumps and valves, is the 5VDC 30Amps relay shown in figure 9(a). The utilized wireless communication is the same hardware units utilized in developing the sensor wireless module. The control unit for this design is the microcontroller based Arduino Nano board, shown in figure $3(\mathrm{~b})$

Sizing the PV system; To power all components in the module, as well as, the attached actuator, solar PV power supply and storage unit is sized as follows: since all actuators are 12 VDC operating, the selected battery is the AGM battery $120 \mathrm{AH} 12 \mathrm{~V}$ Syrio, rechargeable miniaturized, solar battery shown in figure 9(b). The suitable solar panel is the 120W, 12VDC Mono-crystalline solar panel, shown in Figure 9(c), with 21.6V open voltage $\left(\mathrm{V}_{\mathrm{oc}}\right)$ and $7.72 \mathrm{~A}$ short circuit current $\left(\mathrm{I}_{\mathrm{sc}}\right)$. Good charge controller choice is the $20 \mathrm{~A} 12 / 24 \mathrm{~V}$ EP solar. For powering the control unit, sensors and relay drives with 5VDC, a voltage regulator circuit module to drop voltage from 12 VDC to $5 \mathrm{DCV}$ is required, a good choice is AMS1117 step down power supply module $5 \mathrm{DCV}$ voltage regulator $6.5 \mathrm{~V}-12 \mathrm{~V}$ to $5 \mathrm{~V}$ and shown in figure $9(\mathrm{e})$.

The pictorial diagram representing the hardware design and integration of the wireless solar powered actuator module is shown in figure $9(\mathrm{f})$.

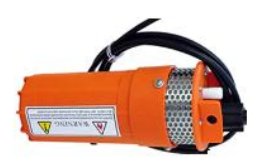

(a)

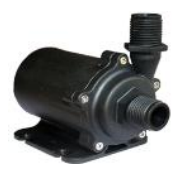

(c)

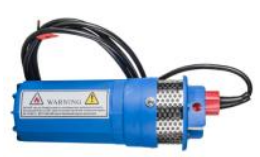

(b)

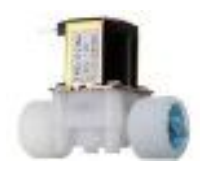

(d)
Figure 8. Proposed pumps and valves: (a) $12 \mathrm{~V}$ DC Submersible Water Pump; (b) YM2440-30 6LPM submersible pump; (c) VP50E $12 \mathrm{~V}$ solar powered water pump; (d) $12 \mathrm{~V}$ Electric Solenoid Valve.

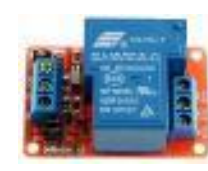

(a)

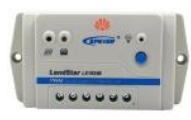

(c)

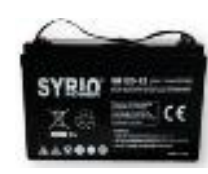

(b)

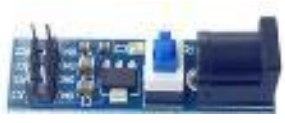

(d)

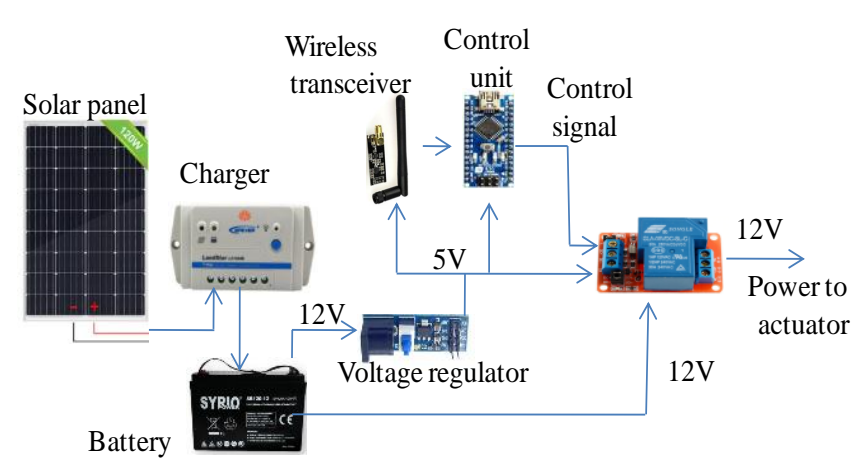

(f)

Figure 9. Proposed drive interface elements and circuit for driving Pumps and valves: (a) 5VDC 30Amps relay; (b) 12 VDC deep cycle miniaturized solar battery; (c) 20A 12/24V EP charge controller; (d) Step down voltage regulator 6.5-12V to $5 \mathrm{~V}$; (f) The pictorial diagram representing the hardware design and integration of the wireless solar powered actuator module.

\section{4 local well state managing module design}

To monitor the water level in local well and control water pumping process to a green area specific section, a standalone solar powered module with wireless communication is deigned.

As shown in the pictorial diagram in figure 10, the module consists of the following hardware components; $12 \mathrm{~V}$ solar PV unit, 12V DC submersible water pump, surface storage water tank, Arduino Nano as control unit, wireless communication unit and VP50E $12 \mathrm{~V}$ water pump to pump water from storage tank to a green area section. The solar PV unit is sized similar to one of the wireless actuator module design.

The data acquired is send to the main control unit wirelessly to main control unit to consider the level and state in decision making. The control unit in this module, controls the data transmission/relieving, pumping of water to the surface tank and to the of the green area. 


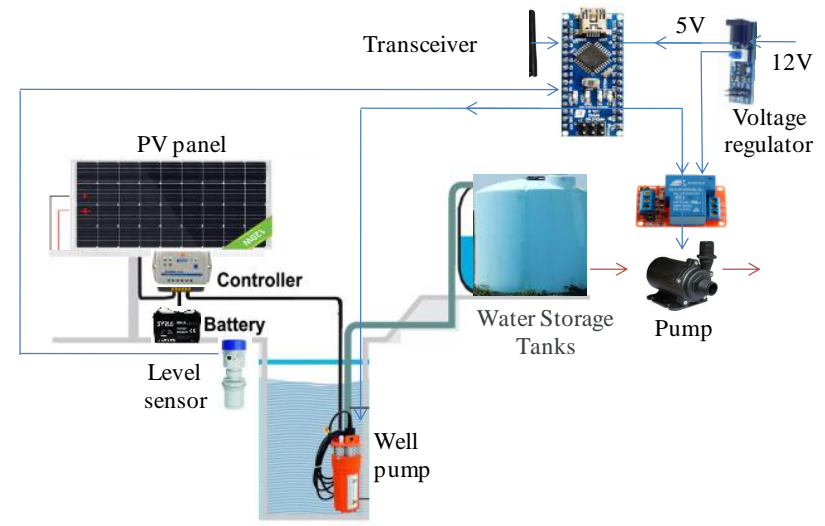

Figure 10. The pictorial diagram representing the hardware design and integration of well state managing and pumping module.

\subsection{Main control unit module design}

All the data about the whole green area's sections, including the readings from all sensor modules with local decisions, readings from well status module, climatic weather conditions module are send wirelessly to the main control unit, that is programmed with control algorithm that coordinates the whole irrigation process. Arduino mega is used as the control unit for this module, the solar PV power unit designed for the sensors module is applied to power this module. The main control unit design with hardware components is shown in the pictorial diagram in figure 11 .

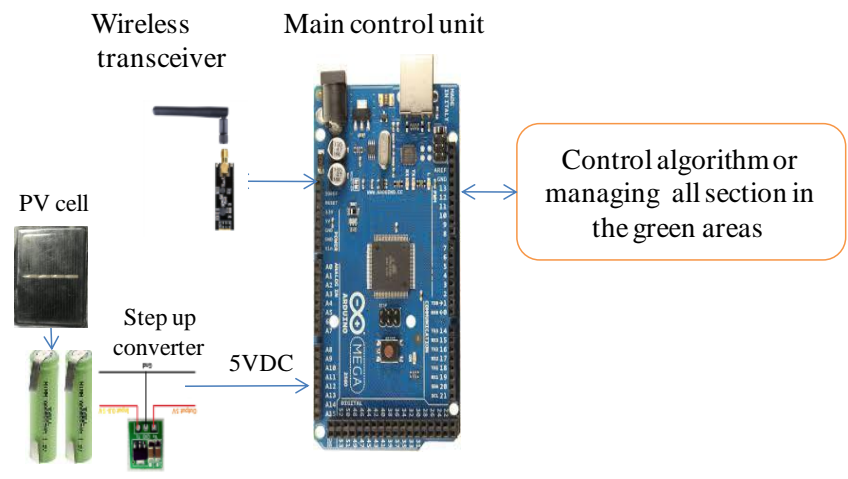

Figure 11. Pictorial diagram representing the main control unit for controlling the whole irrigation system.

\subsection{Supervisor data monitoring and recording module design}

Module design is suggested as shown in figure 12, and intended to allows the supervisor to monitor, and to intervene and control the irrigation process at the whole university, as well as, for data recording, monitoring and analysis. Wireless transceiver module is used to receive all the readings from all modules with local decisions, climatic weather conditions and well status. This data is processed, analyzed and recorded, and can be displayed.
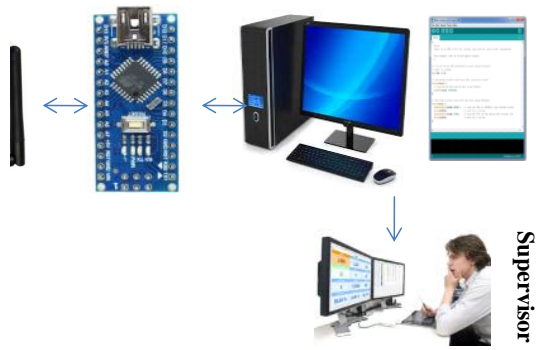

Figure 12. Supervisor data monitoring and recording.

\section{Control algorithm design and representation}

The system to control the irrigation process in the whole university is shown in figure 13 , the control algorithm is developed to acquire data from several points and based on collected data take decisions regarding to the whole irrigation process, as well as take local decision regarding to local sections. The control algorithm for the sensor module and the actuator module are represented using flowcharts as shown in figure 14(a) and 14(b) respectively.

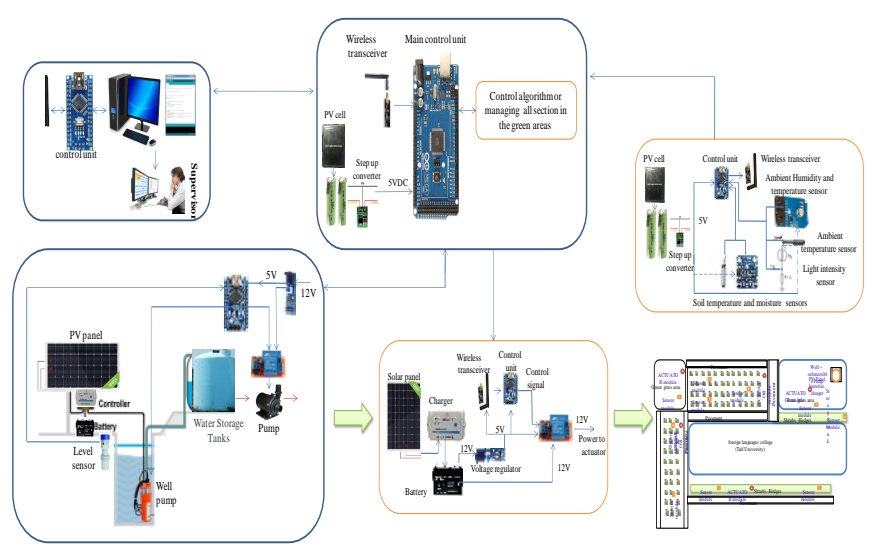

Figure 13. Whole irrigation process system design with all modules and components at university.

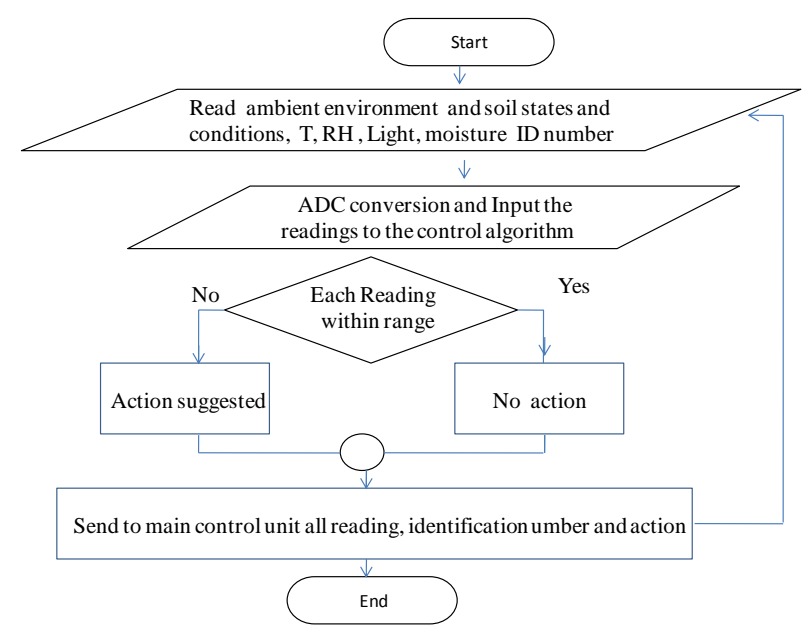

(a) 


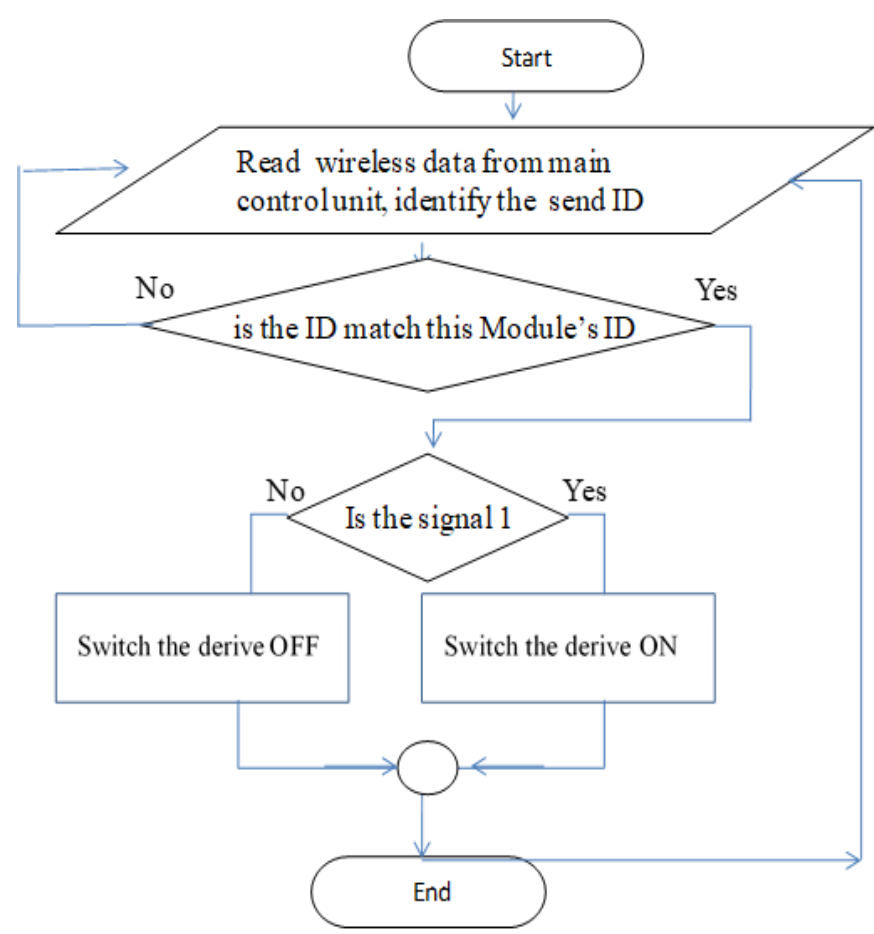

(b)

Figure 14. Control algorithm flowcharts: (a) Sensor module; (b) Actuator module.

\section{CONCLUSIONS}

In this work, wireless automated solar powered irrigation control system was designed based on five sub-modules, each model designed to be standalone solar powered and wireless controlled. The system proposed based on dividing all green areas into sections, each section is given an identification number, also, each section depending on the dimensions, is equipped with corresponding number of standalone, solar powered, wireless sensor and actuators modules, to acquired data and implement the taken decisions for specific section. The system is developed to monitor and control the irrigation process based on ambient states and conditions on the ground, as well as, the supervisor's input, the microcontroller based on main control unit module is designed and programmed with control algorithm, which is developed to process and analyze acquired data, predict the atmosphere state and take decisions, based on time, available volume of water in the well and soil state. The designed system provides both a conceptual design and a blueprint for practical implementation of wireless standalone solar powered smart irrigation control systems for managing water using in green areas of smart universities.

\section{ACKNOWLEDGMENT}

This research was supported by Research Groups Program funded by Deanship of Scientific Research, Taif University, Ministry of Education, Kingdom of Saudi Arabia (grant number: 1-440-6140).

\section{REFERENCES}

[1]. Soliman, M. S.; Alahmadi, A. A.; Maash, A. A.; Elhabib, M. O., Design and Implementation of a Real-Time Smart Home Automation System Based on Arduino Microcontroller Kit and LabVIEW Platform. International Journal of Applied Engineering Research 2017, 12 (18), 7259-7264.

[2]. Alahmadi, A. A., Developing a wireless real-time automated home approach utilizing NI MyRIO microcontroller board and LabVIEW platform. Indonesian Journal of Electrical Engineering and Computer Science 2019, 16 (3), 1273-1278.

[3]. Soliman, M. S.; Dwairi, M. O.; Sulayman, I. I. A.; Almalki, S. H., Towards the design and implementation a smart home automation system based on internet of things approach. International Journal of Applied Engineering Research 2017, 12 (11), 2731-2737.

[4]. Suresh H Ballla, K. R. M., P. Renuka, Dr . I. Satyanarayana,, Design and Implementation of Automatic Irrigation System Using Wireless Sensor Network and Based on Web Platform. International Journal of Electrical Electronics \& Computer Science Engineering 2017, 4 (5), 144-147.

[5]. Khan, S.; Hafeez, M.; Rana, T.; Mushtaq, S., Enhancing water productivity at the irrigation system level: A geospatial hydrology application in the Yellow River Basin. Journal of Arid Environments 2008, 72, 1046-1063.

[6]. Selvath, D.; Salivahanan, S.; Ganesan, I.; Kumar, K. R.; Thamaraiselvi, S., Fuzzy logic based intelligent control for irrigation system. 2003, 20, 199-203.

[7]. Liu, Y.; Ren, Z.-H.; Li, D.-M.; Tian, X.-K.; Lu, Z.-N., The Research of Precision Irrigation Decision Support System Based on Genetic Algorithm. 2006; p 3123-3127.

[8]. Zaier, R.; Zekri, S.; Jayasuriya, H.; Teirab, A.; Hamza, N.; Al-Busaidi, H., Design and implementation of smart irrigation system for groundwater use at farm scale. 2015.

[9]. Sales, N.; Remédios, O.; Arsénio, A. M., Wireless sensor and actuator system for smart irrigation on the cloud. 2015. 
International Journal of Engineering Research and Technology. ISSN 0974-3154, Volume 13, Number 5 (2020), pp. 891-899

(ㅇ) International Research Publication House. https://dx.doi.org/10.37624/IJERT/13.5.2020.891-899

[10]. Khelifa, B.; Amel, D.; Amel, B.; Mohamed, C.; Tarek, B. In Smart irrigation using internet of things, 2015 Fourth International Conference on Future Generation Communication Technology (FGCT), 29-31 July 2015; 2015; pp 1-6.

[11]. García-Paucar, L.-H.; Diaz, A.; Viani, F.; Robol, F.; A.Massa, Decision support for smart irrigation by means of wireless distributed sensors. 2015.

[12]. Jalal, A. S. A.; Fawzi, N. A., Design and Implementation of Smart Irrigation System Using Wireless Sensor Network Based on Internet of Things. International Journal of Scientific \& Engineering Research 2017, 8 (4), 109-113.

[13]. Arduino Weather Station Project - Hydreon Rain Sensor. http://cactus.io/projects/weather/arduino-weather-station -rain-sensor (accessed 06/01/2020). 